\title{
Specific Adsorption of Halide Ions on Iron Surface: A Combined Electrochemical and Monte Carlo Simulation Investigation
}

Lei Guo ${ }^{1, *}$, Yiman $O u^{1}$, Xun Shen ${ }^{1}$, Savaş Kaya ${ }^{2}$, Wei Shi ${ }^{1}$, Renhui Zhang ${ }^{1}$, Xingwen Zheng ${ }^{3}$, Junjun Wang $^{4}$

${ }^{1}$ School of Material and Chemical Engieering, Tongren University, Tongren 554300, China

${ }^{2}$ Department of Chemistry, Faculty of Science, Cumhuriyet University, Sivas 58140, Turkey

${ }^{3}$ Material Corrosion and Protection Key Laboratory of Sichuan province, Zigong 643000, China

${ }^{4}$ College of Materials Science and Engineering, Chongqing University of Technology, Chongqing 400054, China

*E-mail: cqglei@163.com

doi: $10.20964 / 2017.08 .04$

Received: 7 April 2017 / Accepted: 22 May 2017 / Published: 12 July 2017

The specific adsorption effect of halide ions (i.e., $\mathrm{Cl}^{-}, \mathrm{Br}^{-}, \mathrm{I}^{-}$) on the surface of mild steel in acid media has been explored by electrochemical and Monte Carlo simulating methods. The electrochemical impedance spectroscopy (EIS) and Tafel polarization results demonstated that the mild steel was protected from corrsion to some extent when $\mathrm{KX}(\mathrm{X}=\mathrm{Cl}, \mathrm{Br}, \mathrm{I})$ exist. The absorption strength was determined by calculating a customized parameter, namely, adsorption efficiency, which suggest that absorption ability, in descending order of magnitude, was $\mathrm{I}^{-}, \mathrm{Br}^{-}$, and $\mathrm{Cl}^{-}$. Moreover, Monte Carlo simulation was employed to look for the most stable adsorption configurations of halide ions onto $\mathrm{Fe}(110)$ surface. Our experimental findings were in accordance with the theoretical analysis.

Keywords: Halide ions, Specific adsorption, Iron surface, Electrochemical, Monte Carlo simulation

\section{FULL TEXT}

(C) 2017 The Authors. Published by ESG (www.electrochemsci.org). This article is an open access article distributed under the terms and conditions of the Creative Commons Attribution license (http://creativecommons.org/licenses/by/4.0/). 